\title{
HACIA UNA IGLESIA «LÍQUIDA»
}

DOI: https://doi.org/10.52039/seminarios.v62i217.128

ARNAUD JOIN-LAMBERT*

El fin de la cristiandad ha sido anunciado y después constatado por numerosos autores durante los últimos cincuenta años. Lo característico es la radicalidad y la irreversibilidad del cambio en la relación entre Iglesia y sociedad. Las regiones más fuertemente (cuantitativamente) y profundamente (cualitativamente) evangelizadas vienen experimentando un descenso y una marginalización progresiva de iglesias, de cristianos y de los valores que representan. La parroquia, que ha sido la estructura de base de esta cristiandad desde el siglo XI, es confrontada directamente por estos cambios.

Desde 1998, Alfonso Borras viene proponiendo el término «remodelaje» para caracterizar estas mutaciones ${ }^{1}$. Con él pretende describir la progresión de las modificaciones de las estructurales locales de la Iglesia católica. Las investigaciones más recientes sobre la parroquia constatan que ha comenzado una nueva fase mucho más radical ${ }^{2}$.

El desafío que se le plantea a la Iglesia empieza a ser convertirse en una minoría que es católica (abierta a lo universal) y no encerrada en sí misma, una minoría asumida conscientemente y no pasiva. Los antiguos modelos se enfrentan a sus límites, al mismo tiempo que se produce el agotamiento de los agentes de pastoral ${ }^{3}$. El vocabulario de «atrio» o de «umbral» ha aparecido para describir esta intención que se esfuerza por desbordar los muros parroquiales. Pero hoy resulta difícil «inventar las parroquias del mañana» ${ }^{4}$. En este contexto, las palabras del papa Francisco resuenan con fuerza:

* Es profesor de Teología en la Universidad Católica de Lovaina (UCL Louvain-la-Neuve). El presente artículo ha sido traducido por Jorge Miguel Fraile Fabero, sobre el original Vers une Église «liquide»: Études 4213 (février 2015) 67-78.

1. Alfonso Borras es autor de una veintena de artículos sobre el tema, cf. La paroisse, et au-delà...: Études 402 (2005) 783-793.

2. A. Join-Lambert, Évolutions et avenir des paroisses et des Églises. Aperçu de recherches et réflexions récentes: Ephemerides Theologicae Lovanienses 90 (2014) 127-151.

3. Cf. Burn-out, épuisement des agents pastoraux: Lumen vitae 68/3 (2013).

4. Tema del concilio provincial de las diócesis de Lille, Arras et Cambrai (2013-2015). 
Debemos reconocer que la llamada a la revisión y a la renovación de las parroquias no ha dado todavía los frutos suficientes para que estén más próximas si cabe a la gente, que sean lugares de viva comunión y de participación, y que se orienten por completo hacia la misión ${ }^{5}$.

Para esta reflexión que mira al futuro, proponemos el adjetivo «líquido», según la noción de liquidez que aplicó a la sociedad Zygmunt Bauman en el 2000, y después a la Iglesia Pete Ward en el $2002^{6}$.

1. «INCUBADORAS», «START-UPS» Y «CITYKIRCHEN», ALGUNAS INICIATIVAS RECIENTES

La aparición en este principio de siglo de modalidades renovadas de presencia de la Iglesia en ciertos lugares no parroquiales es muy significativa. Son realidades de la Iglesia que presentan a menudo una fecundidad y un verdadero dinamismo. Dejamos que nos iluminen dos libros recientes, que se fijan en lo que crece y dejan de lado tanto las disfunciones como aquello que está muriendo ${ }^{7}$.

Nos situamos ante proyectos que, por analogía, denominamos las «incubadoras» y las "start-up». Surgidas en el ámbito de la investigación científica, directamente en contacto con la industria y los servicios, las incubadoras son agrupaciones de personas con alta cualificación y comprometidas en el desarrollo de proyectos innovadores. Aplicados al catolicismo actual, las incubadoras son proyectos de una cierta amplitud, caracterizados por la innovación, iniciados por instituciones eclesiales, diócesis y congregaciones religiosas que trabajan en el medio urbano. Promueven un itinerario espiritual individual, pero por encima de todo la confluencia de personas en temas comunes. Estos encuentros generan a su vez proyectos o asociaciones temporales o duraderas bien entre cristianos o bien con no cristianos «de buena voluntad». En Francia pueden señalarse, a modo de ejemplo, tres grandes proyectos: «Nuestra Señora de Pentecostés», en torno a la plaza de la Défense; «San José», en Grenoble, para la pastoral de jóvenes, y «Marta y María», que se centra en la acogida, en el

5. Papa Francisco, exhortación apostólica Evangelii gaudium (2013), 28.

6. Z. Bauman, Modernidad líquida, Fondo de Cultura Económica, México 2004, Tiempos líquidos: Vivir una época de incertidumbre, Tusquets, Barcelona 2007; Vida líquida, Planeta, Barcelona 2012; P. Ward, Liquid Church, Wipf \& Stock, Eugene (OR) 2013.

7. P. Goudreault, Chemins d'espérance pour l'avenir de l'Église, Lumen vitae, Namur 2010; C. Henneke, Glänzende Aussichten: Wie Kirche über sich hinauswächst, Aschendorff, Münster 2011. 
nuevo barrio Humanicité, en Lomme (Lille). Una denominación bastante recurrente y certera es la de "casa de la Iglesia». Asimismo puede mencionarse la «Capilla de la Resurrección», en Bruselas, junto a las instituciones europeas, «lugar» ecuménico muy activo y lleno de de proyectos.

En otra escala, se presentan proyectos cristianos de tipo start-up, a imagen de esas empresas de servicios o de tecnología nacidas con pocos medios y llevadas por algunos individuos motivados por una innovación. Esos lugares dirigidos por cristianos pueden estar ligados a una actividad económica, por ejemplo, cafés o albergues en los cuales la dimensión de hospitalidad es central ${ }^{8}$. La analogía de la Iglesia con una casa de huéspedes ayuda a percibir que nada es posible si no los hay. Alrededor de la hospitalidad, estas iniciativas se inscriben en una espiritualidad cristiana, uno de cuyos referentes es el evangelio de la Visitación. La creatividad se despliega en ocasiones de maneras sorprendentes, como la «Church on the corner», renovación de una antigua taberna-bar en Islington. Otros proyectos son de tipo asociativo: biblioteca, hospedería en el camino de Santiago, etc.

Desde hace algún tiempo, en el ámbito alemán se lleva hablando y reflexionando sobre las Citykirchen. Se trata de proyectos, tanto católicos como protestantes, cuya nota distintiva es ir a las «periferias» existenciales. Son proyectos específicos de la nueva realidad socio geográfica de la City, caracterizada por la concentración de servicios y comercios, y por el descenso del hábitat familiar. Por estos lugares pasa mucha gente de manera puntual; se trata de lugares abiertos a todos, descritos como "oasis de silencio», «espacios de maduración de la fe» o «de descanso». Estas Citykirchen pueden ser una iglesia (no parroquial o que antes fue parroquia) remodelada para la finalidad del proyecto y con espacios propios, es decir, con una construcción que se adapta a la finalidad que se busca. Las iglesias históricas o turísticas son en ocasiones muy propicias para esto. Una multiplicidad de nombres manifiesta esta diversidad: por ejemplo, Kulturkirche, Jugendkirche, Angebotskirche o Diakoniekirche ${ }^{9}$. En general no son parroquias (lugares donde una comunidad de fieles más o menos estable vive el «todo para todos» parroquial), ni lugares para la celebración

8. Cf. Kirche als Gasthaus: Diakonia 44/1 (2013).

9. www.citykirchenprojekte.de, red que reagrupa 62 proyectos, con un congreso cada dos años. 
dominical. En estos lugares viven a menudo solteros que se desplazan y personas mayores que ya no lo hacen, inmigrantes y personas en riesgo de pobreza. Esto propicia una «especialización» de la oferta espiritual.

Cuando los agentes pastorales no están comprometidos «por todo» y «para todos» como en las parroquias tradicionales (particularmente en los funerales, los sacramentos y la catequesis), estas iniciativas liberan tiempo y energías para hacer cosas más creativas, puntuales y de tipo evento. Las Citykirchen proponen también exposiciones o conciertos, al igual que actividades sociales (ayuda a emigrantes, a personas en riesgo de pobreza, etc.) y educativas (formación, conferencias, intercambios, etc.). Internet y las redes sociales les sirven para la promoción y la comunicación. Esta presencia abierta en la ciudad (como se define la Liebfrauenkirche en Fráncfort) requiere de medios: apertura amplia, personas cualificadas y voluntarios para llevar a cabo la acogida y el acompañamiento. Esto implica un respaldo importante por parte de las instituciones o el compromiso de congregaciones religiosas. Además, hace falta la adaptación suficiente para realizar proyectos acordes al medio y una apertura para facilitar las innovaciones.

Tanto para las «incubadoras» como para las «start-ups» el desafío mayor es posibilitar y cuidar el reencuentro. El contacto directo y físico con quienes están alejados de las parroquias es el objetivo común de estas iniciativas. Se sitúan donde pasa el mayor número de personas. Que las iglesias tengan directamente o no la iniciativa de estos proyectos, hace ver claramente que hoy están expuestas al desafío de la misión «para todos», que las parroquias ya no cumplen.

Se trata de multiplicar los espacios que, sin tener como fin ocuparse de todo, puedan al menos congregar a quien lo desee alrededor de una dimensión de la existencia, de la hospitalidad, de la convivencia o del apoyo. Si es relativamente fácil poner a disposición «edificios significativos», a menudo emblemáticos en los centros urbanos, resulta en general costoso invertir en ellos tanto en la reparación material como en la puesta a disposición de personal cualificado y voluntario para este tipo de misión. La llamada y la motivación de laicos en su ámbito de competencias y según sus gustos y deseos permite desarrollar esta presencia en el mundo. Lo que ya existe refleja las buenas bases de su compromiso. Para la Iglesia se trata de proyectarse de una manera diferente y de desarrollar su misión, que denominaremos la «parroquia líquida», figura concreta de una Iglesia que se ha trasformado en líquida. 


\section{DE LA SOCIEDAD LÍQUIDA A LA IGLESIA LÍQUIDA}

Desde la reflexión de Zygmunt Bauman sobre la sociedad líquida, la noción de liquidez ha sido aplicada en muchos ámbitos. Una sociedad líquida se caracteriza por la primacía de las relaciones, de la comunicación, de la lógica de la red, a diferencia de una sociedad sólida que privilegia las instituciones y la estabilidad socio geográfica. Nos interesan aquí las reflexiones desarrolladas por los teólogos anglosajones, especialmente Pete Ward. Aplicada a la Iglesia, la liquidez traduce muchos cambios específicos: una vida cristiana que se basa en la actividad espiritual y no en las estructuras; que no está centrada en el precepto dominical; que integra esa parte creciente de personas que comienzan o vuelven a comenzar y no los fieles de siempre; que tienen una permanencia limitada en el tiempo dentro de una determinada iglesia.

¡El problema no está en aquellos que vienen todavía a las parroquias, si no en todos aquellos que no vienen! Las iglesias miden su éxito en el número de "practicantes», incluso cuando afirman la necesidad de todos. Y no haciendo más que responder a las necesidades de algunos, las parroquias ignoran o no atienden de hecho la sed espiritual del mayor número de personas ${ }^{10}$. La reorganización actual de la parroquia apenas sí consigue alcanzar a nuevas personas, renovando a veces sin embargo el compromiso de quienes vienen todavía ${ }^{11}$.

Según Ward, cuando la Iglesia local comienza a parecerse a un club, es urgente reformarla. Esta iglesia-club es una respuesta a la pregunta dramáticamente realista de Ward: ¿Por qué tan poca gente ve la Iglesia como un lugar donde encontrar lo que buscan? Las parroquias estarían de hecho incapacitadas para cumplir el deseo de auténticas expresiones espirituales que se expresan fueran de ellas mismas, dejando esto a comunidades religiosas envejecidas o a nuevas debilitadas por la amplitud del desafío.

A partir de esta constatación compartida, surge un interrogante que concierne a la función o la perennidad de las actuales parroquias. La metáfora de la liquidez puede verse a través de tres imágenes. A Ward no le interesan las parroquias fijas, pues sólo contempla la liquidez total, en la

10. Así, «la lógica de la taquilla», L. Villemin, Service public de religion et Communauté. Deux modèles d'ecclésialité pour la paroisse: La Maison de Dieu 229 (2002) 59-79; lógica conocida en el mundo anglosajón como «parish-hop o parish shop and hop».

11. Como lo muestra el estudio reciente llevado a cabo en Bretaña por L. Plouchart, en B. Merdrignac (dir.), La parroise, communauté et territoire. Constitution et recomposition du maillage paroissial, Presses Universitaires, Rennes 2013, 19-63. 
que se va a dispersar el cristianismo para dar hoy un sentido a la vida de los hombres (como la sal se disuelve en el agua). Ve en ello una forma de salir de sí hacia ese destino común que puede dar el sabor de Cristo.

En su libro Aquachurch ${ }^{12}$, Leonard Sweet desarrolla la imagen de la Iglesia como un «barco». Ella conserva una parte de solidez, de permanencia, en un mundo que se ha vuelto fluido, aunque sin arraigo social o cultural. Sweet insiste sobre el cambio de contexto más que sobre los cambios a realizar en la Iglesia. La Iglesia se vuelve aquí una especie de arca de Noé.

Para ilustrar la complejidad de esta relación sólido / líquido, proponemos aquí más bien la imagen de un precipitado de química. La mezcla de dos líquidos apropiados provoca un precipitado de efectos sólidos, visibles y de duración (aunque a veces inestables). En la postmodernidad, los dos componentes, sociedad e Iglesia, son líquidos. La segunda tendrá que ajustarse y diversificarse de modo que el reencuentro con la primera suscite una reacción, un precipitado sólido (incluso inestable) y visible en los diferentes medios y culturas. Una Iglesia que saliera a las periferias, con un estilo apropiado, sería capaz de ver cómo brota sentido y esperanza allí donde no existe.

\section{UNA IGLESIA «PARA TODOS»}

Esta cuestión de la auto comprensión de la Iglesia en el mundo actual es crucial para determinar las modalidades de su misión. Traemos aquí a colación la figura del extranjero según Michel de Certeau para describir la relación de la Iglesia y la sociedad emergente. La Iglesia es una sociedad -la solid church según Ward-, o sea, «se constituye diferenciándose [...]; plantea un 'fuera' para que exista un 'entre nosotros'; fronteras para que se dibuje un país interior; 'otros' para que el 'nosotros' tome cuerpo ${ }^{13} »$. Y sin embargo, ya en 1945 Certeau intuía que el riesgo inherente a la Iglesia era la crispación y el aislamiento en todos los ámbitos. Setenta años más tarde la situación acentúa la urgencia del desafío que tiene por estas fronteras. Las parroquias están de facto reservadas a algunos, aunque esto sea contrario a su razón de ser, pues ellas están orientadas en principio «para todos». La solución o conversión propuesta por Certeau consiste

12. L. Sweet, Aquachurch: Essential Leadership Arts for Piloting Your Church Today's Fluid Culture, Loveland (CO) 1999. Poco antes, él había usado la misma metáfora de la liquidez en Soultsunami: Sink or Swim New Millennium Culture.

13. M. de Certeau, L'Étranger ou l'union dans la différence: Études 1 (janvier 1945) 402. 
en permitir que Dios tenga una plaza como extranjero, a imagen del extranjero en el camino de Emaús (Lc 24). Esto conduce a un descontrol y a un despojamiento como factores esenciales para pensar el ser humano. Todo reencuentro es entonces pascual en la fe, implicando una salida de sí, que en ocasiones es paralela a una muerte por un desplazamiento que engendra abundancia de vida.

La figura del extranjero se despliega así como característica de la identidad del cristiano en este mundo. En la Carta a Diogneto (siglo II), el cristiano es llamado paroikos (etimología de parroquia), es decir, el extranjero que se aloja en la ciudad gozando de derechos pero sin ser ciudadano. De este modo, el cristiano, que es igual al otro habitante, testimonia su diferente adhesión a las «realidades del cielo», pero sin privilegios, esparcido en el mundo como el alma en el cuerpo. Dieciocho siglos más tarde, la pertenencia de los cristianos a una Iglesia líquida no les sitúa fuera de la sociedad líquida, si no que les invita a darle un sentido, sin limitación.

La parroquia no puede desaparecer en sí misma, puesto que si no los católicos renunciarían a lo que constituye el corazón de su misión tal como la conciben desde siempre: anunciar una buena noticia para todos, en todas las naciones. Pero la parroquia no puede quedar aquí reducida a la figura histórica de los últimos siglos, sino que ha de incluir todas sus formas actuales. La parroquia «tiene una gran plasticidad, puede tomar formas muy diversas que incluyen la docilidad y la creatividad misionera del pastor y de la comunidad» ${ }^{14}$. Por esta razón, la palabra "parroquia» puede conservarse, pero añadiendo un calificativo, solida o líquida, para designar o bien la estructura heredada del siglo XI, o una realidad nueva donde la precedente no sería más que una parte.

\section{UNA IGLESIA EN RED}

No es inédito aplicar a la Iglesia la noción de red. El cambio es aquí considerar de manera nueva la vieja misión de la parroquia sólida y asumir de manera diferenciada los componentes del «todo» y de "en un lugar». Las parroquias sólidas no serían más que elementos de las parroquias líquidas.

Considerando la vida eclesial actual, se podría proyectar una estructuración de estas parroquias líquidas (en red) a través de las tres dimensiones siguientes. 
En primer lugar, el acompañamiento a lo largo de la vida, la proximidad, las raíces, esto sería lo propio de un lugar estable por grados, como puntos de referencia en largos periodos de las existencias que se mueven. Es también el lugar de la eucaristía regular. Esto quedaría como un resto de las viejas parroquias sólidas que tendrán entonces que renunciar a la vana ilusión de querer cubrirlo todo. Esta parroquia ya conoce novedades misioneras que la van modificando un poco en todas partes de Europa (grupos de oración, cursillos, grupos bíblicos, etc.). Vemos que estas iniciativas renuevan a los de dentro, «fidelizan» a algunos de fuera, pero apenas van más lejos. Entre los ensayos más simples, dentro de las parroquias actuales, la multiplicación de los «domingos de otra forma» es beneficiosa, hace bien ${ }^{15}$. Esto contribuye claramente a construir una nueva vida de la Iglesia para aquellos que van habitualmente y algunos del entorno. Hay que potenciarlo.

La segunda dimensión es aquella del acontecimiento, del despliegue de carismas, de la creatividad. Los estudios empíricos sobre las actuales parroquias sólidas muestran su incapacidad -con muy raras excepciones- para suscitar este impulso hacia las periferias existenciales, en el centro de la cultura actual. Las parroquias no llegan más que al atrio, al umbral. Más «lejos», en lugares reales y virtuales se vive y se despliega el reencuentro, particularmente con el otro al que las parroquias sólidas no alcanzan. La clave está aquí en la experiencia del diálogo, experiencia que desplaza a cada uno, que mueve a veces y obra sobre el Otro. La esencia de estas iniciativas variadas es la circulación de la palabra que, para el cristiano, no se encuentra nunca muy lejos de la Palabra. La característica propia de esta dimensión es la creatividad y la fusión de iniciativas: aquello que los cristianos atribuyen a una escucha activa del Espíritu Santo. En las grandes ciudades este impulso es fundamental. Es aquí donde el mensaje estará de acuerdo con la exhortación del papa Francisco: «La pastoral en términos misioneros exige abandonar el confortable criterio pastoral del 'siempre se ha hecho asi'” ${ }^{16}$.

La tercera dimensión es la mística, escasamente desarrollada por los actores actuales y poco considerada en los proyectos pastorales. La mística es necesaria, por una parte, para reducir el riesgo de polarización estéril de las dos primeras; y por otra, para constituir una vida espiritual más intensa, tanto en la experiencia puntual como en las experiencias progresivas de profundización. En las casas de oración y de reparadora soledad, esta

15. Así, H. Derroitte, Les formes de catéchèse communautaire. Fondements, balises, évaluations, Lumen vitae, Namur 2015.

16. Papa Francisco, Evangelii gaudium, 33. 
dimensión mística ha sido asumida por religiosos y religiosas que se sitúan a menudo a parte de la parroquia ya desde sus orígenes. Allí también el genio creativo debe aparecer para renovar las modalidades de presencia en el mundo de una vida consagrada, en relación con otras dimensiones. Por ejemplo, la noción de «clausura monástica» podría ser renovada.

Bauman insiste sobre el efecto negativo de la postmodernidad: una inseguridad creciente del individuo y su aislamiento. La posibilidad de una comunidad es para él problemática. El deseo comunitario es utópico ${ }^{17}$. Los cristianos están entonces confrontados al ingente desafío de seguir proponiendo diversas modalidades para que el «para todos» sea tenido en cuenta. Anunciar el Evangelio pasa a consistir más que antes en cuidar la pequeña comunidad, a pasar del hogar al oikós cristiano ${ }^{18}$. Esta primacía de las relaciones humanas en la acción evangelizadora permite alimentar las comunidades estables o pasajeras que tienen sentido en la vida de las personas. La expresión «familia de Dios», tan presente para guiar el horizonte de las comunidades católicas en África, no dice otra cosa. Este primado de la relación es una verdadera oportunidad para el cristianismo, porque pertenece a su genio propio (sin ser por ello un monopolio) de tomar en serio y acompañar concretamente al ser humano como un «ser en relación».

El reto de las parroquias líquidas consiste en alimentar y mantener la comunión entre las comunidades en las diversas dimensiones analizadas. Lo que se juega es más que una simple articulación. Se trata del bien de la comunión. Esto influye, como no podría ser de otra manera, en el modo de abordar la cuestión adyacente y compleja del líder y de las responsabilidades.

\section{CINCO FIGURAS DE AUTORIDAD}

Al «todo para todos en un lugar» de la parroquia sólida, la parroquia líquida añade un «por todos», el cual debe verse como la llamada de todos los bautizados y la posibilidad de cada uno de desplegar lo que es capaz para el anuncio del Evangelio. La parroquia líquida de mañana será la realización concreta de numerosas afirmaciones del Concilio Vaticano II. Se trata de dar protagonismo a los carismas y las vocaciones, expresados en los deseos y discernidos en Iglesia, haciendo presente y realmente el

17. Z. Bauman, Modernidad líquida, 37.

18. Por retomar un término revalorizado por Don Pigi, «inventor» de las células parroquiales de evangelización en su variante católica. 
«sacerdocio común» del que se habla tanto desde hace medio siglo. Pero ese «por todos» no podrá desplegarse si no es con figuras de autoridad a su servicio. De forma realista, pensamos aquí en la intensificación de los consejos y equipos actuales en las tres dimensiones de la parroquia líquida, con líderes bien identificados.

Para no caer en la utopía estéril, los elementos de la realidad marcan nuestro camino. La dimensión de lo cotidiano y de la proximidad (la actual parroquia sólida) estaría ejercida por la figura del sacerdote; la dimensión de la salida a las periferias, por la figura del capellán (quizá ¿una figura diaconal?); la dimensión de la vida espiritual y «mística», por la figura del monje, la monja o el director/a espiritual (el experto espiritual como un tipo de líder). Así se mantendría un tríptico familiar en la Iglesia católica, pero a partir de ahora articulado sin jerarquía de preeminencia. El reto principal es aquí una reconfiguración del ministerio curial pensado hasta el presente para cubrirlo todo.

Una cuarta figura está vinculada a la comunión. Si el obispo tiene y tendrá siempre el ministerio de comunión en la Iglesia local y con la Iglesia universal, ¿cómo pensar este ministerio en el nivel de las parroquias líquidas? Ya no será aquel tipo de obispo, si no hay un aumento improbable de las diócesis por diez o veinte. El nuevo ministerio necesita de competencias reconocidas para dirigir una realidad compleja. Este podría ser un «coordinador profesional», sin saber aquí si debería estar ordenado o no.

Se ve que las reformas "parroquiales» no pueden olvidarse de una reflexión sobre las reformas diocesanas. El realismo invita a considerar el «nivel» del arciprestazgo como aquel del despliegue de la parroquia líquida. El coordinador (arcipreste) asume entonces un ministerio adjunto al ministerio pastoral del obispo, teniendo por finalidad el velar para el buen funcionamiento de las tres dimensiones. En este esquema, la presidencia de la eucaristía es en primer lugar aquella del obispo en la Iglesia local, pero también la del cura-sacerdote. Es imposible concebir la primera dimensión del tríptico, que no estuviera estructurada alrededor de la asamblea eucarística. Las modalidades de acceso al ministerio presbiteral y su ejercicio quedan por eso formuladas como una amplia tarea, dado el decrecimiento en el número de sacerdotes.

Una quinta figura que debería tener su lugar en las parroquias líquidas es la del teólogo. En efecto, si nadie se preocupa de la puesta en perspectiva, de la exploración y proyección teórica, del discurso racional en diálogo con las ciencias, entonces las parroquias líquidas no podrán desplegarse de manera adecuada en las culturas posmodernas. 


\section{AvanZa EN LAS AgUAS PROFUndas (Lc 5,4$)$}

Ghislain Lafont señalaba en 2011 la ilusión de que «las reformas de estructura serían suficientes para renovar la cara de la Iglesia y asegurar la evangelización» ${ }^{19}$. Es cierto, pero hay que avanzar para que la Iglesia no se vuelva un museo o el refugio de algunas personas motivadas o muy habituadas. El tiempo de la pastoral de cristiandad que otorgaba al cura de la parroquia el protagonismo y las ovejas de un territorio perfectamente delimitado ha cambiado de forma definitiva. Es hora de la polivalencia, de los cambios de orientación y de las rápidas mutaciones.

El mérito de una reflexión alrededor de la liquidez es proponer algunas hipótesis para que el Evangelio pueda continuar y sea anunciado a todos en los vacíos de la sociedad occidental, según las modalidades de sociabilidad y expresión cultural de nuestro tiempo. Tenemos conciencia de que nuestros propósitos son ciertamente menos pertinentes para el catolicismo del medio rural. Pero en todas partes, para evocar de nuevo la lejana Carta a Diogneto, los cristianos están plenamente en el mundo y están sometidos a las mismas leyes antropológicas.

Iniciar proyectos es esencial para la misión cristiana. Pero tal cosa sólo tiene sentido mirando las «leyes extraordinarias y verdaderamente paradójicas de su república espiritual».

19. G. Lafont, L'Église en travail de réforme. Imaginer l'Église catholique II, Cerf, Paris $2011,307$. 